Supplement of Biogeosciences, 14, 4905-4925, 2017

https://doi.org/10.5194/bg-14-4905-2017-supplement

(C) Author(s) 2017. This work is distributed under

the Creative Commons Attribution 3.0 License.

(c) (1)

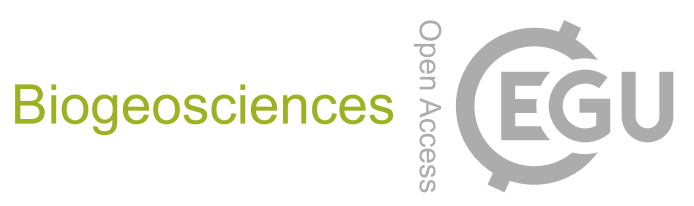

Supplement of

\title{
The influence of environmental variability on the biogeography of coccolithophores and diatoms in the Great Calcite Belt
}

Helen E. K. Smith et al.

Correspondence to: Helen E. K. Smith (helen.eksmith@gmail.com)

The copyright of individual parts of the supplement might differ from the CC BY 3.0 License. 
Table S1: Spearman's rank correlation coefficients for the environmental variables. Significant correlations are denoted as follows: $\mathbf{p}<\mathbf{0 . 0 0 0 1} * * *$, $\mathbf{p}<0.001 * *, \quad \mathbf{p}<0.01 *, \mathbf{p}<\mathbf{0 . 0 5}$

\begin{tabular}{|c|c|c|c|c|c|c|c|c|c|c|c|}
\hline & SST & Salinity & MLD & $\mathrm{E}_{\mathrm{MLD}}$ & TOxN & $\mathrm{PO}_{4}$ & $\mathrm{Si}(\mathrm{OH})_{4}$ & $\mathrm{NH}_{4}$ & $A_{T}$ & $C_{T}$ & $\mathrm{pH}$ \\
\hline Salinity & $0.781^{* * *}$ & & & & & & & & & & \\
\hline MLD & $-0.596 * *$ & -0.474 & & & & & & & & & \\
\hline $\mathrm{E}_{\mathrm{MLD}}$ & $0.681 * * *$ & $0.621 * *$ & $-0.903 * * *$ & & & & & & & & \\
\hline TOxN & $-0.945 * * *$ & $-0.821 * * *$ & $0.641 * *$ & $-0.729 * * *$ & & & & & & & \\
\hline $\mathrm{PO}_{4}$ & $-0.963 * * *$ & $-0.807 * * *$ & $0.625 * *$ & $-0.711 * * *$ & $0.961 * * *$ & & & & & & \\
\hline $\mathrm{Si}(\mathrm{OH})_{4}$ & $-0.667 * *$ & -0.429 & 0.520* & -0.467 & $0.702 * * *$ & $0.700 * * *$ & & & & & \\
\hline $\mathrm{NH}_{4}$ & $-0.798 * * *$ & $-0.648 * *$ & $0.507 *$ & -0.459 & $0.704 * * *$ & $0.753 * * *$ & $0.637 * *$ & & & & \\
\hline$A_{T}$ & $-0.953 * * *$ & $-0.781 * * *$ & 0.518* & $-0.600 * *$ & $\mathbf{0 . 8 9 0}^{* * *}$ & $0.918 * * *$ & $0.672 * * *$ & $0.819 * * *$ & & & \\
\hline$C_{T}$ & $-0.981 * * *$ & $-0.814^{* * *}$ & 0.581* & $-0.669 * * *$ & $0.959 * * *$ & $0.981 * * *$ & $0.690 * * *$ & $0.774 * * *$ & $0.946 * * *$ & & \\
\hline $\mathrm{pH}$ & 0.137 & 0.309 & -0.189 & 0.285 & -0.378 & -0.326 & -0.424 & 0.005 & -0.105 & -0.261 & \\
\hline$\Omega_{\text {calcite }}$ & $0.962 * * *$ & $0.835^{* * *}$ & $-0.567 *$ & $0.684 * * *$ & $-0.961 * * *$ & $-0.979 * * *$ & $-0.684^{* * *}$ & $-0.728 * * *$ & $-0.900 * * *$ & $-0.983^{* * *}$ & 0.352 \\
\hline
\end{tabular}




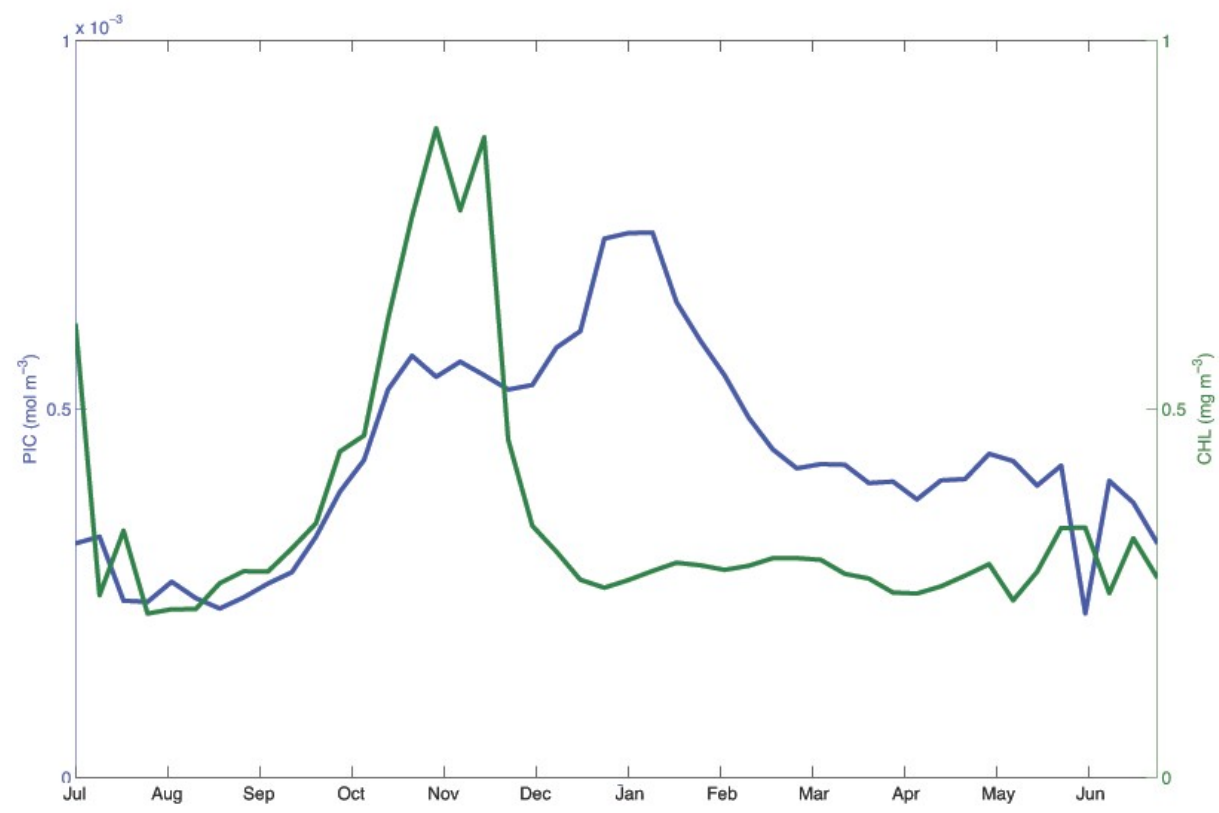

Figure S1: Chl $a$ (green) and PIC (blue) climatological (10 year averaged) time series for the area $42-47^{\circ} \mathrm{S}$ and $48-53^{\circ} \mathrm{E}$, surrounding Crozet Island courtesy of Jason Hopkins. The PIC peaks around two months later (January - February) than the Chl $a$ peak (November) in this region of the Great Calcite Belt 

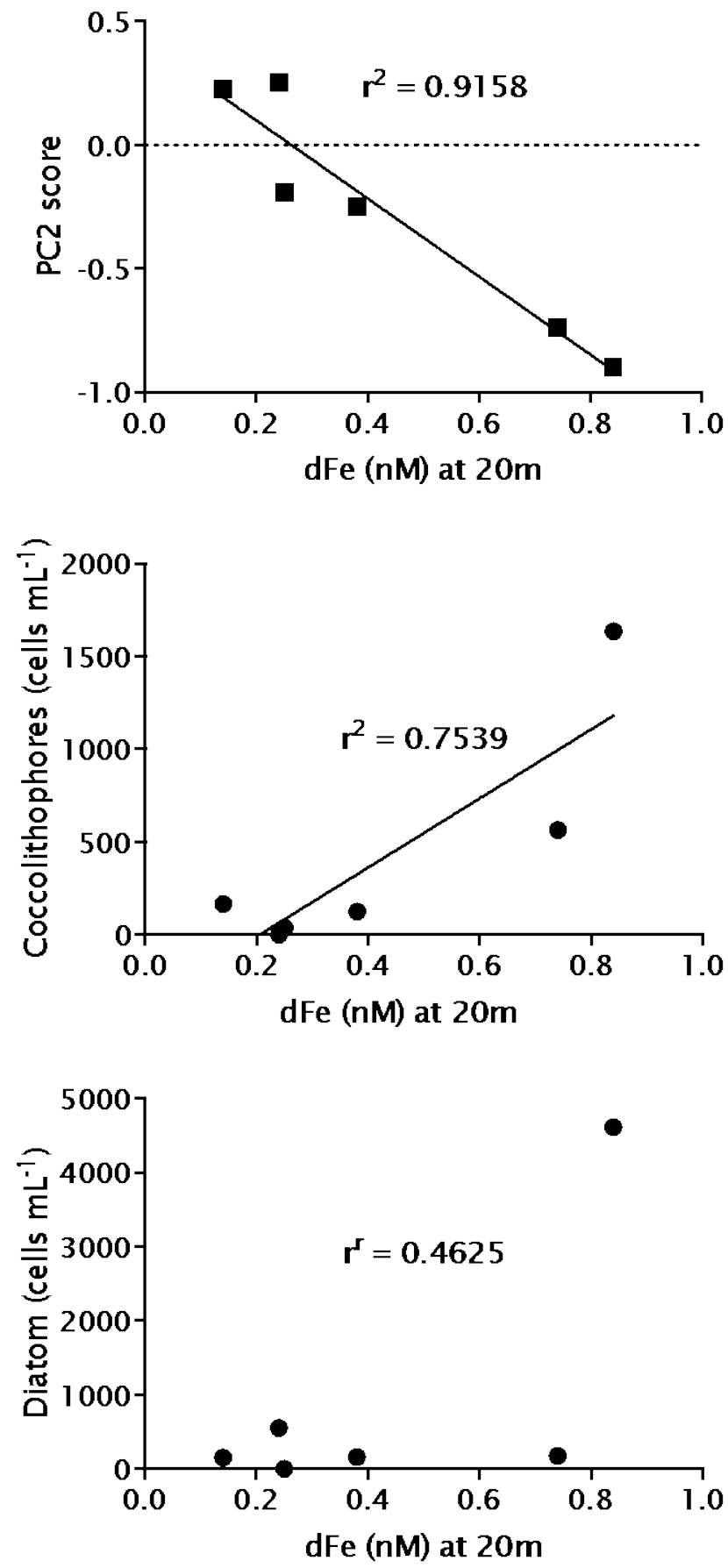

Figure S2: Relationships between dissolved iron in the GCB and (A) PC2 scores; (B) Coccolithophore abundance; (C) Diatom abundance 